\title{
SOCIOLOGIA E LITERATURA: UM EXERCÍCIO TEÓRICO SOBRE AGÊNCIA, RUPTURAS E PERMANÊNCIAS A PARTIR DE NIKETCHE - UMA HISTÓRIA DE POLIGAMIA
}

\author{
Jacqueline Carvalho da SILVA*
}

RESUMO: Utilizar um texto literário como uma porta para acessar e pensar sobre as dinâmicas sociais no campo da agência é o exercício proposto neste artigo. Primeiro se discute brevemente os desafios da sociologia da literatura desde a demarcação do seu campo em relação a crítica literária aos limites e possibilidades da literatura como objeto de análise sociológica. Posteriormente, através da obra literária Niketche: uma história de poligamia se realiza um exercício teórico, utilizando a teoria da prática em Ortner (2007), para entender a trajetória da personagem principal, Rami, que oscila entre ruptura e aquiescência à situação subalterna feminina. Niketche nos abre uma porta para pensar sobre as relações de gênero em Moçambique, apesar de tratar-se de uma obra ficcional (talvez justamente por isso!).

PALAVRAS-CHAVE: Literatura. Sociologia. Agência. Rupturas. Permanências.

\section{Introdução}

Em 1990, Paulina Chiziane publicou Balada de Amor ao Vento e tornouse a primeira mulher a publicar um romance em Moçambique. Niketche: uma história de poligamia foi publicada em 2002 e, tendo a personagem principal como narradora, conta a história de uma mulher (Rami), dona de casa, casada há vinte anos e mãe de cinco filhos, que, diante da ausência de seu marido (Tony), decide

\footnotetext{
UFPE - Universidade Federal de Pernambuco. Programa de Pós-graduação em Sociologia. Recife PE - Brasil. 50670-901 - scarvj@gmail.com.
} 
ir em busca das mulheres com as quais ele mantém relações extraconjugais. A narração torna-se um testemunho da situação da mulher no país, já que as cinco mulheres de Tony são de zonas distintas de Moçambique: Rami é de Maputo (sul), Julieta de Inhambame (centro), Luísa de Zambésia (centro norte), Mauá (Macua) e Sally (Maconde), no norte. Fica evidente também a tensão entre a tradição e a nova ordem pós-independência, onde a poligamia é proibida, porém se mantém de modo informal.

A narração do livro oscila entre ruptura e aquiescência de Rami à situação subalterna feminina em Moçambique, apontando para a capacidade das mulheres de resistir, exercer certo poder no âmbito doméstico e alçar uma posição laboral de sucesso, apesar da situação de dominação masculina. O desfecho da obra aponta para a possibilidade de ruptura das relações de poder masculino sobre as mulheres através da entrada as mulheres no mercado de trabalho. Isso não significa a superação da desigualdade entre homens e mulheres nesse contexto, porém, ainda que as estruturas de poder masculino se mantenham fortemente pela tradição, há espaço para a resistência.

O objetivo do presente artigo é apontar na obra literária Niketche a trajetória de resistência e aquiescência de Rami, a partir das noções de agência em Sherry Ortner (2007). Ortner (2007) aponta a possibilidade de compreender agência como um elemento colado à estrutura social, propondo uma teoria da prática, ao modo de Giddens e sua teoria da estruturação (1979), nos dando a possibilidade de compreender o movimento de mudança iniciado por Rami, a partir do seu discurso que oscila entre resistir e aceitar o lugar de desprestígio ocupado pelas mulheres tanto na cultura tradicional quanto no momento pós-colonização portuguesa.

Antes de iniciar propriamente o exercício de aplicar a perspectiva de Sherry Ortner (2007) na interpretação das ações da personagem principal de Niketche, vale discutir brevemente os desafios da sociologia da literatura desde a demarcação do seu campo em relação à crítica literária, bem como os limites e possibilidades de ter uma obra literária como objeto de análise sociológica, o que deixará mais claras as pretensões do presente artigo.

\section{Sociologia, literatura e desafios}

O campo da sociologia da literatura precisa lidar constantemente com o fato de ter a obra literária como objeto de estudo. Isso incita embates com o campo da crítica literária que reclama para si a capacidade de lidar com o funcionamento próprio da obra literária que obedece a regras que seriam da competência da linguística. 


\section{Sociologia e literatura: um exercício teórico sobre agência, rupturas e permanências a partir de Niketche - uma história de poligamia}

Costa Lima (2002) é um dos autores que é partidário da ideia de que na sociologia a literatura perde importância própria e se torna epifenômeno do tecido social. A obra literária tornar-se-ia um documento revelador da realidade social e seria minimizada enquanto objeto de estudo dotado de uma forma específica. $\mathrm{O}$ autor reconhece que a sociologia pode conectar a obra com o lugar social onde ela foi concebida, com o seu contexto socio-histórico, porém, afirma que o significado da obra literária não está em si, mas na interpretação de quem lê. Assim, critica: é possível pensar em análises sociológicas da literatura que só são capazes de ver o que a teoria ilumina, mas toda interpretação sociológica permite uma contra interpretarão. Desse modo, para Costa Lima (2002), a apreciação sociológica não pode vir em primeiro lugar. É preciso focar primeiro no entendimento da raiz ficcional do objeto estudado, estar mais próximo da análise específica do objeto discursivo analisado. Por isso a necessidade de parcerias entre sociólogos y teóricos da literatura, que estariam mais aptos a detectar a especificidade do objeto de estudo em questão.

É claro que toda obra partilha do social, e Costa Lima (2002, p. 681) assim o entende, o problema para ele é como verificar essa parte social da obra sem torná-la apenas veículo do que é o social: "O paradoxo do romance é o de toda obra de arte: ela é irredutível a uma realidade que, entretanto, traduz". A proposta de Costa Lima (2002) seria combinar o estudo do contexto histórico da obra com um conhecimento preciso das características do discurso a ser analisado. Assim seria possível evitar dois erros: minimizar a obra literária como apenas ilustração do social e estetizar a obra, descolando do contexto onde foi produzida.

Uma perspectiva mais flexível em relação ao campo da sociologia da literatura é trazida por Antonio Candido (1976) que aponta a necessidade de se chegar a um meio termo em relação à análise sociológica da literatura vis-à-vis à análise estética, no campo da crítica literária. Não se trata de apontar nem uma nem outra como primordial, mas de entender a literatura "fundindo texto e contexto numa interpretação dialeticamente íntegra" (CANDIDO, 1976, p.04.). Aí entra a necessidade de reconhecimento dos limites e possibilidades de cada disciplina:

O tratamento externo dos fatores externos pode ser legítimo quando se trata da sociologia da literatura, pois esta não propõe a questão do valor da obra, e pode interessar-se justamente por tudo que é condicionamento. Cabe-lhe, por exemplo, pesquisar a voga de um livro, a preferência estatística de um gênero, o gosto das classes, a origem social dos autores, a relação entre as obras e as ideias, a influência da organização social, econômica e política, etc. É uma disciplina de cunho científico, sem a orientação estética necessariamente assumida pela crítica (CANDIDO, 1976, p. 04). 
Assim, a proposta de Candido (1976) nos aponta que compreendendo a polissemia das obras literárias e as distintas maneiras de analisá-las, é possível um estudo sociológico de uma obra literária sem necessariamente a análise dos aspectos estéticos de sua estrutura interna. É possível também fazer um duplo caminho: identificar os aspectos sociais presentes nas obras e perceber como esses elementos podem funcionar estruturando-as do ponto de vista da forma e da estética. Nessa segunda acepção, o interno e externo já não se separam, o elemento social torna-se expresso na própria construção formal e estética do texto.

Sendo este um artigo situado no campo da sociologia, tomarei a posição de Candido (1976) como norte e procurarei analisar a trajetória da personagem principal da obra Niketche de Paulina Chiziane, a partir das noções de agência propostas por Ortner (2007). Trata-se de um exercício de aproximação ao contexto socio-histórico em que o livro é escrito através do aspecto formal e estético da obra literária. Assumimos então que, os aspectos internos (ou formais) e externos (ou sociais) à obra não podem ser separados neste tipo de análise. Lançamos o olhar sobre a trajetória da personagem Rami ao longo do livro, iniciada como uma história de anuência da posição subalterna feminina no casamento e um lamento pela poligamia ilegal vivida pelo marido e que, aos poucos, se transforma em resistência e acaba por reconfigurar as relações do marido com ela e com as outras mulheres.

É preciso, porém, deixar claro os desafios e limitações presentes neste tipo de análise. A obra literária apesar de ser ficcional traz consigo elementos de um contexto socio-histórico. Por isso, é preciso tomá-la como uma porta à realidade histórica do país, especialmente no que tange a posição social das mulheres em Moçambique, para identificar esses elementos sociais que interessam para a análise. Porém, o ficcional também nos interessa como discurso, atribuído não apenas à autora. Claro que todos temos um lugar de fala e esse lugar de fala não é absolutamente moldado pela estrutura. Ele é muito mais fluido, envolve status, poder, uma história de vida. Aceitando essa pluralidade, a produção literária pode ser entendida como discurso de um indivíduo, mas parte da sociedade da qual é impossível desligar-se.

Além disso, admitimos que todo estudo sociológico é sempre orientado teoricamente e, portanto, há outras perspectivas e exercícios válidos para a análise da obra. A crítica de Costa Lima (2002) a respeito do significado da obra literária não estar em si mesma, mas nos olhos, por vezes guiados pela teoria, de quem a lê e, portanto, sempre permite contra interpretação, não invalida os estudos sociológicos da literatura. Uma vez expostos os pressupostos e marco teórico da análise, um estudo no campo da sociologia da literatura passará pela validação do campo acadêmico da mesma forma que todos os outros estudos do campo na sociologia, que é uma ciência multiparadigmática. Sendo assim, não pretendemos aqui esgotar as possibilidades de análise, apenas propor um exercício teórico para apontar uma 


\section{Sociologia e literatura: um exercício teórico sobre agência, rupturas e permanências a partir de Niketche - uma história de poligamia}

das possibilidades de compreender a capacidade de agência da mulher na sociedade Moçambicana a partir da trajetória da personagem Rami em Niketche: uma história de poligamia.

\section{Agência, rupturas e permanências: a trajetória de Rami}

As noções de agência propostas por Ortner (2007, p. 45) têm como pressuposto a ideia de que "a cultura constrói as pessoas como tipos particulares de atores sociais - mas atores sociais mesmo assim - embora sua vivência concreta de práticas variáveis reproduza ou transforme - normalmente um pouco de cada - a cultura que os fez". Sob essa perspectiva da teoria da prática, agência e estrutura não se opõem, mas se interpenetram sem que haja uma sobreposição de uma sobre a outra:

[...] nem os 'indivíduos' nem as 'forças sociais' têm 'precedência', [mas na qual] há, contudo, uma relação dinâmica, forte e, às vezes, transformadora entre as práticas de pessoas reais e as estruturas da sociedade, da cultura e da história (ORTNER, 2007, p.50).

Assim, todos os indivíduos são agentes, mas estão imbricados nas relações sociais, o que impossibilita-nos dizer que são absolutamente livres para agir. A agência, porém, é possível dentro dos limites da estrutura que por sua vez vai sendo afetada pelas ações e suas consequências intencionais e não intencionais, possibilitando outros cursos de ação, sendo possível então pensar tanto em reprodução quanto em mudança social através da ação individual. Essa definição de agência em Ortner é parte do processo que Giddens (1979) chamaria de estruturação: "o fazer e refazer de formações sociais e culturais mais amplas" (ORTNER, 2007, p. 52). É preciso pontuar também que Ortner (2007) propõe pensar agência dentro de uma perspectiva em que o indivíduo está imerso em relacões de poder, de desigualdade e de competição, bem como em relações de solidariedade.

A trajetória de Rami pode ser entendida por essa perspectiva teórica, uma vez que se trata de uma mulher socializada nos moldes de uma cultura machista formada tanto pela tradição moçambicana quanto pela presença colonial portuguesa, que após de anos de aceitação, age diante das traições conjugais do marido e seus novos cursos de ação, juntamente com o contexto em que está inserida, permitem novos cursos de ação possíveis. Em suas ações iniciais Rami não tem a intenção de quebrar com as expectativas tradicionais e desiguais em seu casamento, sua intenção primeira era apenas recuperar seu marido ausente. 
Agência aqui, sob a perspectiva de Ortner (2007), se refere as ações intencionais, diferenciando-as das ações de rotina. Essas duas categorias não podem ser totalmente separadas, são mais como um contínuo entre ações de rotina e ações com um fim específico. Está em jogo a intencionalidade da ação, menos presente na obra de Giddens (1979), e mais destacada por Ortner (2007). Não se trata de entender que toda ação humana é intencional, há uma série de ações de rotina com resultados não esperados ou racionalizadas pós-ação, onde também atua o inconsciente e a intencionalidade como um processo que não domina totalmente o foco dos indivíduos durante suas ações. Mas nos interessa aqui as ações voltadas para um fim mais claro pois essa abordagem nos leva a focar mais adiante na relação agência e poder. Assim Ortner (2007) diferencia práticas de rotina e agência, vista precisamente como ação mais intencional.

Entendendo agência como intencional (mas não necessariamente totalmente consciente), todos os seres humanos são dotados da capacidade de agir, mas há uma distribuição desigual de recursos para tal. As relações de poder, porém, são em alguma medida instáveis e passiveis de resistência por parte dos dominados, que sempre possuem algum grau de agência, ainda que limitado. Desse modo, em Ortner (2007) temos duas acepções para definir agência: ações intencionais ativas (ou a perseguição de projetos culturalmente definidos) e agência em contexto de desigualdade (podendo ser tanto agir exercendo poder - dominação - ou agir contra o poder - resistência.). A perseguição de projetos pode significar a vontade de realizar algo no âmbito pessoal (conseguir um emprego, uma viagem, a passagem para a idade adulta, e no caso de Rami, recuperar seu marido) ou envolver estruturas mais amplas como conservar uma língua, resistir à invasão territorial, lutar pelos direitos das mulheres, etc. Essas duas possibilidades estão circunscritas culturalmente e só podem ser entendidas dentro da estrutura social em que os agentes estão inseridos e a transformam e reproduzem.

A história de Rami começa quando se dá conta de que, apesar de cumprir com o seu papel de mulher submissa, seu marido, Tony, estava sempre ausente. O primeiro impulso para ação vem através do seu encontro com uma imagem no espelho, que surge no livro como um alter ego que aponta para cursos de ação diferentes dos que tem tido, decide lutar. Mas lutar pelo que?

Como é que o Tony me despreza assim, se não tenho nada de errado em mim? Obedecer sempre obedeci. As suas vontades sempre fiz. Dele sempre cuidei. Até as suas loucuras suportei [...]. Hoje quero mudar o meu mundo. Hoje quero fazer o que fazemos todas as mulheres desta terra. Não é verdade que pelo amor se luta? Pois hoje quero lutar pelo meu. Vou empunhar todas as armas e defrontar o inimigo, para defender o meu amor (CHIZIANE, 2002, p. 14). 


\section{Sociologia e literatura: um exercício teórico sobre agência, rupturas e permanências a partir de Niketche - uma história de poligamia}

Sem ser consciente do que fazer exatamente para realizar seu projeto, Rami vai até a casa das amantes, uma a uma, para lutar fisicamente pelo Tony, mas descobre que todas tem o mesmo destino: serem abandonadas por ele, que sempre sai em busca de outras. É o espelho que diz a Rami: "Agrediste a vítima e deixaste o vilão. Não resolveste nada” (CHIZIANE, 2002, p.27).

O projeto de Rami é recuperar seu marido e para isso passa a buscar uma série de maneiras para consegui-lo: conselhos na família, uma conselheira do amor, magia. Tudo sem sucesso. Não se trata de uma empreitada contra o poder masculino e sua posição subalterna como mulher, trata-se a princípio de reestabelecer seu casamento. Enquanto conta sua história, sua empreitada para descobrir a maneira de ter o marido de volta, ela vai refletindo sobre o que é ser mulher e identificando o papel secundário que ela ocupa. É então que Rami vai pouco a pouco rompendo com sua posição passiva e, junto com as outras mulheres de Tony, toma uma série de atitudes que questionam o poder masculino e passa a ter um projeto de resistência "nas margens do poder" como definiria Ortner (2007, p. 68). Assim, Rami tem um projeto pessoal que é superar suas rivais para voltar a ter Tony em casa, sem alterar mais nada na ordem das coisas. Tal projeto acaba por ir se transformando ao longo do tempo, quando vai se relacionando com as outras mulheres e novos cursos de ação vão tornando-se possíveis.

A diferenciação entre agência de poder (seja como resistência, seja como dominação) e agência de projetos também não pode ser tomada como estanque. É possível pensar em perseguição de projetos em contextos de desigualdade, o que nos levaria a agência como dominação, quando o dominador busca realizar seus projetos, ou como resistência, quando é o dominado que busca realizar os seus:

As pessoas em posições de poder têm - legitimamente ou não - o que poderia ser considerado "muita agência", mas também os dominados sempre têm certa capacidade, as vezes muito significativa, de exercer algum tipo de influência sobre a maneira como os acontecimentos se desenrolam. Portanto, resistência também é uma forma de "agência de projeto" (ORTNER, 2007, p. 64).

A própria noção de resistência pode ser entendida como a busca pela possibilidade de exercer uma agência de projetos. Pessoas dominadas podem manter a agência tanto resistindo quanto tentando construir e perseguir seus projetos mais individuais ou mais coletivos. Essas relações de poder são chamadas por Ortner (2007) de jogos sérios. A possibilidade de resistência está sempre presente, ainda que não se concretize, ainda que seus resultados sejam mínimos, presentes apenas nas relações micro sociais. 
Diante da situação que vive, com um marido ausente e com quatro outras famílias, Rami se vê sem saídas para recuperá-lo e começa a avaliar a poligamia, que tradicionalmente era aceita e que foi proibida com a colonização. Apesar das mudanças na cultura tradicional, tanto a poligamia, de forma informal em todo país, quanto as escolas do amor e os ritos de iniciação, mais frequentes no norte do país, continuam a existir. É a tia Maria, que viveu um casamento polígamo, que indica que esse sistema quando era permitido dava mais poder às mulheres: "a poligamia tem vantagens. Vantagens? Vantagens, sim. Quando as mulheres se entendem, o homem não abusa" (CHIZIANE, 2002, p.74). A poligamia começa a surgir como possibilidade de adquirir mais poder na relação com Tony.

A essa altura, não há agência de poder, como resistência, frente a Tony ou frente a tradição machista no discurso de Rami. Sua estória começa justo quando sai da posição passiva e torna-se ativa no projeto de recuperar seu marido e manter o status quo, e os efeitos não pretendidos dessa ação acabam por se revelar aos poucos, transformando o próprio projeto inicial de Rami em resistência nas margens do poder. É assim que, em busca de conseguir realizar seu projeto de ter o Tony por perto e sem mais saídas, Rami resolve reunir as mulheres e apresentá-las na festa de cinquenta anos de Tony, na frente de toda a família. Se na prática tinha um marido polígamo, decide tornar a situação pública e se vingar expondo-o a todos. Isso a torna a primeira mulher e lhe dá direitos na família. Juntas e reconhecidas, tornam-se mais fortes. A estória começa a dar um giro. Essa é a primeira de uma série de ações que questionam o poder de Tony sobre suas relações.

A segunda é quando Rami, consciente das dificuldades de depender economicamente de Tony, consegue dinheiro e empresta às outras mulheres de Tony. Elas montam um negócio, têm sucesso e pagam suas dívidas. Rami se junta a uma delas para vender roupas no mercado e, em companhia de outras mulheres, também vai aprendendo maneiras de resistir ao controle do marido para com o dinheiro ganhado. Em conversa no mercado com as mulheres Rami conta:

Digo-lhes que presto contas de todos os meus negócios ao meu marido. Digo quanto ganho e quanto gasto. As colegas riem-se. Aos homens nunca se deve prestar contas certas. Os homens foram feitos para controlar e as mulheres para trabalhar. Nenhuma dessas mulheres prestam contas certas aos companheiros e contam-lhes estórias tristes: o dia não rendeu, há muita concorrência no mercado, há ladrões na rua e roubaram-me os produtos todos, não ganhei nada (CHIZIANE, 2002, p.120).

Acabou, por pressão das amigas, a entrar em um sistema de crédito e junto com as suas ainda chamadas rivais (as outras mulheres de Tony) prosperou o suficiente 


\section{Sociologia e literatura: um exercício teórico sobre agência, rupturas e permanências a partir de Niketche - uma história de poligamia}

para não ter que pedir dinheiro ao marido. Tornaram-se todas empreendedoras de sucesso.

Depois veio o lobolo, o reconhecimento das esposas mediante o pagamento de um dote para cada uma. A partir desse momento todas tornaram-se oficiais e fortaleceram-se a ponto de questionar o comportamento de Tony como marido. Diante da descoberta do encontro de Tony com outra mulher, as cinco esposas o convidam para jantar e o questionam sobre ela. Rami já o havia feito quando tinha um casamento monogâmico, mas não tinha conseguido nenhuma explicação. Dessa vez eram cinco contra um: "Ah, Tony. Já não estou sozinha no teu encalço. Agora somos cinco. Quero ver se nos escapas com tua esperteza de rato." (CHIZIANE, 2002, p.127)

A capacidade de resistência feminina torna-se cada vez mais clara. Porém convive com o comportamento submisso em relação ao Tony, que, ao se queixar para a família sobre o comportamento desafiante, ao final não desdiz a obediência de suas mulheres:

numa coisa o Tony tem razão: somos maquinas de obediência. Perfeitas. Se não fôssemos estaríamos já na rua, na lua, a gozar de todos os prazeres dessa vida. Somos obedientes, sim senhor, somos. Por isso estamos aqui gravitando, quais satélites à volta do astro rei (CHIZIANE, 2002, p.157).

As estruturas de poder não foram quebradas, mas há agência de poder, como resistência, claramente presente. A poligamia também se apresenta como uma faca de dois gumes para Rami, ela sofre com o processo de reconhecimento das novas mulheres, mas o aceita como único caminho de manter seu casamento: “francamente falando, não tenho nada a ver com a poligamia. O meu problema já expliquei: se eu reclamo demais, perco o marido todo. Se entrar no seu jogo fico quieta no meu cantinho e ele fica mais pertinho" (CHIZIANE, 2002, p.131). Ao fim e a cabo, quem tem o poder de decidir reconhecido e legítimo a respeito da relação conjugal é Tony, Rami está apenas jogando o jogo utilizando-se do quinhão de agência que possui.

A tradição é um elemento que está sempre presente ao longo da obra. Ela aparece sempre como instrução para a submissão como um destino feminino. Um exemplo disso é quando Rami recebe orientação da sogra para lidar, agora formalmente, com uma família polígama. Tais orientações marcam regras de como servir corretamente a comida ao homem, a necessidade de organizar uma escala conjugal e etc. É a voz da tradição que a narradora rejeita nos seus pensamentos, mas na prática obedece. Sobre os conselhos da sogra, Rami afirma: "essas vozes são sal na brisa, roendo lentamente como salitre. Elas só sabem aquilo que a dor ensina. Não 
conhecem outro mundo senão a própria noite. E colocam a noite aos nossos olhos, como único saber ao seu alcance". (CHIZIANE, 2002, p.127). Apesar disso, ela reúne as mulheres para organizar as tarefas. Rami, mesmo com o poder que usufrui como primeira esposa em relação às outras e da relação que desenvolveram, não é feliz com a situação e ainda as chama de suas rivais. A escala é feita, as comidas e modos de servir são respeitados segundo a tradição. Porém, já nessa nova posição, Rami não quer apenas ter o marido por perto, mas quer vingar-se. Seu projeto começa a transformar-se e sua postura torna-se cada vez mais ativa.

A agência feminina como resistência é motivo de punição, já que ainda de modo micro questiona a ordem estabelecida e suas posições de poder. Tony, portanto, pede o divórcio para punir Rami por sua rebeldia:

Interferes demasiado na minha vida. O teu zelo excessivo me prejudica. Estou zangado contigo desde a data do meu aniversário e toda a trama que me obrigou a assumir compromissos polígamos que eu nem queria. A orgia de vingança foi a gota de água para transbordar tudo. Basta, vamos divorciar-nos (CHIZIANE, 2002, p.166).

Rami, consciente da marginalidade a qual será submetida ao divorciar-se, se nega. Ato seguido, Tony desaparece e acaba dado como morto uma vez que foi encontrado um homem atropelado com características físicas parecidas. Diante disso, Rami cumpre os ritos de viuvez como esposa oficial ${ }^{1}$. Dentre eles há o kutchinga, ${ }^{2}$ um rito de purificação sexual no qual a viúva deve passar uma noite com um homem da família do marido, podendo tornar-se sua mulher. Rami então passa a noite com o irmão de Toni, Levy. Apesar de tratar-se de uma obrigação, Rami desfruta dessa noite: "Ai meu Deus, sinto leveza no meu corpo. Sinto um rio de mel correndo na minha boca. Meu deus, o paraíso está dentro do meu corpo" (CHIZIANE, 2002, p.225).

Na verdade, Tony não havia morrido e tudo aconteceu fruto de um engano. Tony viajou a Paris sem avisar e ao regressar, Rami conta para ele, com prazer, todo o ocorrido. Mais uma vez atua indo de encontro às estruturas de poder e utiliza a tradição para justificar a razão pela qual não resistiu ao ritual de purificação sexual. A tradição aí aparece como aliada na sua resistência, tradição esta que até agora

\footnotetext{
1 O relatório alternativo sobre a situação da mulher em Moçambique apresentado para Comité de Eliminação da discriminação contra as mulheres em maio 2007, aponta, dentre outros temas, para a situação das viúvas no país trazendo alguns relatos. http://www.fidh.org/lMG/pdf/mz042008p.pdf.

2 Em 2012, a prática de kutchinga, que obriga a viúva a envolvimento sexual desprotegido com um parente do defunto, foi abolida, em Moçambique. A abolição foi decretada pela Associação dos Médicos Tradicionais de Moçambique. Fonte: http://www.noticias.mozmaniacos.com/2012/06/ametramo-aboleritual-tradicional.html\#ixzz2saM1y3R0.
} 


\section{Sociologia e literatura: um exercício teórico sobre agência, rupturas e permanências a partir de Niketche - uma história de poligamia}

havia aparecido no discurso de Rami como sempre reservando às mulheres uma posição submissa:

— Não reagiste, não resististe?

— Como? É a nossa tradição, não é? Não me maltratou, descansa. Foi até muito suave, muito gentil. É um grande cavalheiro, aquele teu irmão. Falo com muito prazer e ele sente a dor de marido traído. No meu peito explodem aplausos. Surpreendo-me. Sinto que endureci nas minhas atitudes. O meu desejo de vingança é superior a qualquer força desse mundo" (CHIZIANE, 2002, p.227).

As cinco mulheres, agora bem-sucedidas já não têm mais o tempo disponível para cuidar do Tony e passam de disputar por sua atenção para tentar livrar-se de sua presença em casa. É Saly que deixa clara sua insatisfação:

O que se passa? Ele já está há mais de quinze dias na minha casa e nunca mais sai e vocês nada reclamam. Não fizemos o pacto da partilha, semana aqui, semana ali? Eu também preciso do meu tempo. Quero cuidar dos meus negócios, ganhar dinheiro para criar este filho, e projetar meu futuro. Se nenhuma de vós o quer, eu juro, hei de enxotá-lo a pedrada. Não posso viver com ele eternamente (CHIZIANE, 2002, p.264).

Ju acaba por aceitar recebê-lo, "mas aviso desde já, cuidar dele tornou-se um fardo. Cozinhar para o almoço e jantar. Preparar a mesa, levantar a mesa. Suportarlhes os caprichos a que vocês o habituaram é coisa que nunca mais irei fazer" (CHIZIANE, 2002, p.264).

Daí em diante a posição de poder Tony torna-se cada vez mais frágil. Lu decide casar-se formalmente e o abandona, seguindo os conselhos de Rami. Rami ao ver o sofrimento de Tony, apesar de falar em vingança, ainda sofre pela situação e apesar de ter se aproximado das mulheres continua a chamá-las de rivais. Porém, quando Tony decide que quer ficar apenas com Rami diante da indiferença das outras, ela nega e comunica as rivais os planos do marido. Nenhuma se dispõe a satisfazer os caprichos de Tony e decidem que a solução é encontrar outra mulher para ele. Diante da recusa de Tony, que afirma estar cansado, as outras três mulheres se vão, cada uma com seus amantes, viver suas vidas como primeiras mulheres. Ficam Tony e Rami.

Tony tenta reaproximar-se dela e percebe sua barriga. Está grávida: "Diz que é meu e salva-me" (CHIZIANE, 2002, p.332). Rami reflete sobre o seu poder de dizer sim, tê-lo de volta e realizar aquilo que tanto buscara. Seu discurso torna-se claramente ativo: "Meu Deus, eu sou poderosa, eu sinto que posso salvá-lo dessa 
queda. Tenho nas mãos a fórmula mágica. Dizer que sim e resgatá-lo. Dizer não e perdê-lo. Mas eu o perdi antes o encontrar. Ignorou-me muito antes de me conhecer" (CHIZIANE, 2002, p.333). Sua fala acaba por trazer mais uma vez a tradição como justificativa irônica, agora para sua nova posição de resistência: "Não te posso salvar. Tento salvar-te, mas não consigo, não tenho força, sou fraca, não existo, sou mulher. Os homens é que salvam as mulheres, não o contrário. O filho é do Levy!" (CHIZIANE, 2002, p. 333).

\section{Considerações finais}

A trajetória de Rami iniciada como uma busca pela reprodução da situação social vivida por ela enquanto mulher e esposa, e não pela mudança, acaba por tornar-se uma trajetória de resistência contra o poder masculino e contra a própria tradição que assim o estabelece. As formas como esses elementos de dominação são questionadas como exemplos de agência enquanto resistência nas margens do poder, como define Ortner (2007), uma vez que é através de pequenas brechas que a agência feminina passa de passiva a ativa e ganha espaço para conseguir mudanças. Se entendemos agência ativa como colada aos elementos da estrutura social, fica evidente a razão pela qual é possível ver que a agência da personagem Rami é de início ambígua, mescla rupturas e reproduções com a ordem tradicional das relações de gênero.

A entrada das mulheres no mercado de trabalho, graças à ajuda de Rami, aparece como fundamental para a emergência de novos cursos de ação que vão de encontro as relações tradicionais antes estabelecidas entre Tony e suas esposas. A mudança se dá, porém aos poucos, e não significa a superação definitiva da desigualdade entre homens e mulheres no livro. Trata-se de uma história sobre mudança, mudança através das possibilidades de ação no plano micro, em uma sociedade extremamente desigual no que tange a relações de gênero.

Niketche nos abre uma porta para pensar sobre as relações de gênero em Moçambique, apesar de tratar-se de uma obra ficcional (ou talvez justamente por isso!), e, contribui para reflexões a respeito da resistência como uma possibilidade sempre presente, ainda que oscile entre rupturas e permanências e produza efeitos inicialmente apenas no plano micro social. 
Sociologia e literatura: um exercício teórico sobre agência, rupturas e permanências a partir de Niketche - uma história de poligamia

\title{
SOCIOLOGY AND LITERATURE: A THEORETICAL EXERCISE ABOUT AGENCY, RUPTURES AND REPRODUCTIONS IN NIKETCHE: A STORY OF POLYGAMY
}

\begin{abstract}
This essay is a theoretical exercise that attempts to use a literary text as a window to access and analyze social dynamics and to think about agency in Practice Theory. To begin with, we briefly discuss the difference between a sociological approach of literature and literary criticism. Then, using the notion of Practice Theory by Ortner we analyze the literary work Niketche: a story of polygamy and discuss the journey of the main character, Rami, which oscillates between ruptures with and reproductions of the social role of Mozambican women. Even though Niketche is a work of fiction - or maybe precisely because it is fiction! it is a doorway to understanding and discussing gender relations in Mozambique.
\end{abstract}

KEYWORDS: Literature. Sociology. Agency. Ruptures. Reproductions.

\section{REFERÊNCIAS}

CANDIDO, Antonio. Crítica e sociologia (tentativa de esclarecimento). In: Literatura e Sociedade: estudos de teoria e história literária. São Paulo: Companhia Editora Nacional, 1976. p. 3-15 e p. 17-39.

CHIZIANE, Paulina. Niketche: uma história de poligamia. Maputo: Editorial Ndjira, 2002.

GIDDENS, Anthony. Central Problems in Social Theory: Action, Structure and Contradiction in Social Analysis. Berkeley: University of California Press, 1979.

LIMA, Luiz Costa. A análise sociológica da literatura. In: Teoria da literatura em suas fontes. Rio de Janeiro: Civilização Brasileira, 2002. p. 659-687.

ORTNER, Sherry B. Poder e Projetos: reflexões sobre a agência. In: GROSSI, Miriam Pilar; ECKERT, Cornelia; FRY, Peter Henry (Orgs.). Conferências e Diálogos: saberes e práticas antropológicas. Blumenau: Nova Letra, 2007.

Recebido em 08/02/2018.

Aprovado em 18/04/2018. 
